\title{
Usability of Cloud Computing to Improve Higher Education
}

\author{
Bayan Hashr Alamri, M. Rizwan Jameel Qureshi \\ Faculty of Computing and Information Technology, King Abdulaziz University, Saudi Arabia \\ Email: Bayan.Hashr@hotmail.com, anriz@hotmail.com
}

\begin{abstract}
Cloud computing as a new paradigm has grown from a promising idea to one of the fastest research and development paradigm in education sector. It is a hot research area that applies in all sectors where we require high performance and fast access to resources and services. Cloud computing usability in education is wide-ranging, as acknowledged by many educational institutions around the world. This paper attempts to address the need for utilizing cloud computing in higher education in Kingdom of Saudi Arabia for all the disciplines to raise its level and solve the obstacles that faced the learning process. In addition, cloud computing facilitates educators and students to be more experienced in cloud computing and it prepares them to get benefits of usefulness to become more motivated and effective. Survey is used as a research design to validate the proposed solution. The results show that the proposal to improve higher education is highly supported by the professionals working in the industry and academia.
\end{abstract}

Index Terms - Cloud Computing, Paradigm, Technology, higher education.

\section{INTRODUCTION}

Cloud computing (CC) is a new paradigm that has grown from a promising idea to one of the fastest research and development paradigm in education sector. It is a hot research area that applies in all sectors where we required high performance and fast access to resources and services.

Foster et al. [1] define cloud as a distributed computing model. Cloud computing has lot of benefits such as economical, quality of service, virtualize, scalable, resource sharing and enormous storage. These benefits are delivered to end users on demand over the Internet. It is a distributed paradigm that enables access to virtualize resources. The faculty involved in graduate and post graduate programs can concentrate better on teaching and research due to usage of cloud computing. The main strengths of cloud computing are users can access to anyone, anywhere and whenever needed. The five characteristics of cloud computing are on-demand selfservice, resource pooling, broad network access, rapid elasticity and measured service. The three service models of CC are Software as a Service (SaaS), Platform as a Service (PaaS) and Infrastructure as a Service (IaaS). It has four deployment models that are private, community, public and hybrid cloud [2]. Cloud computing usability in education is wide-ranging and it is acknowledged by many educational institutions around the world. There are many benefits of cloud computing in education institutions such as verity of resources, reduce cost, effective communication, security and privacy. There are many advantages to use $\mathrm{CC}$ in higher education such as support virtualization, reliability, versatility, expandability, service on demand and economical. The applications of cloud computing in higher education will solve many challenges encountered by the educational institutions.

This paper attempts to address the need of utilizing cloud computing in higher education in the Kingdom of Saudi Arabia. The objective of writing this paper is two folds. First task is to improve the quality of higher education and second task is to address the obstacles those are faced during the learning process. Furthermore, this research will help the faculty and students to understand the architectural issues of $\mathrm{CC}$ and effectiveness of using $\mathrm{CC}$ in improving higher education.

The paper is structured as follows. In section II, the related work is introduced. The statement of the problem is described in section III. In section IV, the proposed solution is discussed. The solution is validated using a survey in section $\mathrm{V}$.

\section{RELATED WORK}

$\mathrm{Yu}$ and Yuan [3] present the challenges in studying and implementing the $\mathrm{CC}$ technology in mobile software engineering to find its effectiveness. The mobile users can access a shared computing power or storage on demand. The proposed prototype facilitates the research of exploring the mobile software engineering advancements in cloud computing environment. Cloud Music Player (CMPlayer) is a smart phone music streaming application using Google App Engine at the backend. The main limitation of this application is that it can only be used on Android smartphone and GAE [3].

Engineering incentives in Social Clouds (SCs) present by Haas et al. [4]. SC is a framework in which resources and services are shared between members on the basis of the relationships encoded in a social network [5]. The users of SC should provide resources not only consuming them. The main problem of SC is the need to attract potential and existing participants to share their resources. The attraction of users in SC depends on the relationships 
between the users and scenario of application. It is a good solution to invite more people to become participants in $\mathrm{SC}$ but it is not a complete solution due to trust issues between users [4].

Sazawa et al. [6] discussed Remote Virtual Environment Computing (RVEC) for high-end graphical applications such as Computer Aided Design (CAD). CAD is the use of computer systems to support in the creation, analysis, modification, or optimization of a design. RVEC is a novel remote desktop technology which combines movie compression and still-image lossless compression algorithm (graphics compression) to reduce radically the bandwidth of the image transmission without weakening visual quality. RVEC can lead to ENIGEERINGCLOUD that can provide access to engineering applications from a cloud data center. But, this method is only applied to perform engineering tasks [6].

High-performance cloud computing (HPCC) is presented to merging cloud computing with soft real-time applications by García-Valls et al. [7]. The main examples of soft real-time applications are gaming, video streaming and telecommunication management. It is challenging when these applications are deployed on cloud computing. HPCC help to address the bottlenecks due to execution of its protocol inside the different layers of software stack. The real-time applications have much stronger temporal requirements such as resource guarantees and timely provisioning of results [7].

Elamir et al. [8] present a framework naming programming education environment as cloud computing services to teach computer programming. E-learning applications include educational objectives, content production, content delivery technology, assessment and management component. This framework combines the elements from current practices of E-workbook, Elearning and cloud computing technologies. $\mathrm{C}++$ Workbook as cloud service was implemented to validate the proposed framework. Other services are matters of future work such as logging of programming activities, program plagiarism detection, programming workbook and automatic marking [8].

Sommerville [9] discusses the importance of teaching cloud computing as a part of software engineering courses. It is also covered that what are the most appropriate topics to be included in these courses. The suggested solution is to consider topics of cloud computing from three perspectives. First step is to introduce cloud computing to students. Second step is to practice CC especially in lab oriented courses. Third step is to introduce principles of CC. There is no standard materiel available on cloud computing to teach it in university courses. Another problem is lack of skilled faculty to practice $\mathrm{CC}$ in lab courses [9].

Ding et al. [10] present how to utilize the cloud computing in higher education especially in advanced software engineering courses. Master courses are offered almost in all top universities of the world. Therefore, higher education over cloud will become a medium to share knowledge and resources like electronic (E) books, slides, assignment and projects. A solution is proposed to develop and implement a remote collaboration system based on $\mathrm{CC}$ to practice lab sessions of advanced software engineering courses by Ding et al. [10]. It is proposed that a student of software engineering courses can run, debug, upload and download codes remotely. Cost, security and privacy are some of the constraints of the proposed solution by Ding et al. [10].

Bagchi et al. [11] discuss the utilization of cloud computing in electronic engineering. The proposed solution is to develop a virtual learning system. The system models the circuits and instruments those are used in electronics engineering labs to allow students to carry out experiments, practices and outcomes. The system naming DoCircuits platform is a framework to deal with the tools and it provides learning experience by accessing from any place. There is some future work to enhance the virtual learning system for more effective learning [11].

It is an attempt by Bouyer et al. [12] to develop Elearning system by utilizing cloud computing environment. Another objective is to emphasis on the importance of virtual education to improve the quality of education by applying cloud computing environment. Students can get a range of enormous computing resources anywhere, anytime, less learning time and less cost. Some of the benefits of CC education are improved educational services to enhance teaching and learning in short time span, economical, reduce risk, improve security and strong collaboration [12].

Common Body of Knowledge in Cloud Computing (CBKCC) is an approach to design advanced education and training course on cloud computing [13]. We need a strong technical foundation to build the course materials and different professional group in cloud computing. The current curriculum on cloud computing course aimed to train technical product planners, consultants and engineers. Different groups of cloud professionals and specialists can extend their education and training with the specific knowledge and skills. But, the online curriculum should have basic knowledge in cloud computing and it must be developed with high granularity to allow easy course composition [13].

Parashar et al. [14] discuss large-scale computational and data-enabled science and engineering (CDS\&E) applications to facilitate understanding and managing natural and engineered systems. Clouds are joining highperformance computing (HPC) as platforms for scientific investigation and innovation. These concepts have positioned the clouds as an attractive platform for realworld science and engineering applications. It is important to understand how these applications can effectively utilize such a hybrid infrastructure. But, this will leads to a challenging socio technical research agenda [14].

Ezenwoke et al. [15] discuss the design for national cloud computing model. This model solves the difficulty for education institution to own and use Information and Communication Technology (ICT) facilities. This difficulty attributed to inadequate government funding. After this model, the government would be responsible 
for providing education services to educational institutions in the country. This will bring

Table 1. Limitations of related work

\begin{tabular}{|c|c|}
\hline Title & Limitation \\
\hline $\begin{array}{l}\text { An Approach to Explore Mobile } \\
\text { Software Engineering Advances in } \\
\text { Cloud Computing Environment [3]. }\end{array}$ & $\begin{array}{l}\text { - } \quad \text { Restricted the implementation on Android and GAE. } \\
\text { The need for more improvement in some field in cloud } \\
\text { computing especially, in Mobile Software Segment. }\end{array}$ \\
\hline $\begin{array}{l}\text { Engineering Incentives in Social Clouds } \\
\text { [4]. }\end{array}$ & $\begin{array}{l}\text { - SC based on trust between users, but the level of trust } \\
\text { depends on the type of relationship between people. }\end{array}$ \\
\hline $\begin{array}{l}\text { RVEC: Efficient Remote Desktop for the } \\
\text { ENGINEERINGCLOUD [6]. }\end{array}$ & $\begin{array}{l}\text { The implementation of RVEC based on C++ language and } \\
\text { the platform of the RVEC server and client are Window XP } \\
\text { and Windows } 7 \text {. }\end{array}$ \\
\hline $\begin{array}{l}\text { Challenges in real-time virtualization and } \\
\text { predictable cloud computing [7]. }\end{array}$ & $\begin{array}{l}\text { - Real-time applications have strong timing requirement and } \\
\text { needed predictability guarantees so they still far from a full } \\
\text { adoption of cloud computing. }\end{array}$ \\
\hline $\begin{array}{l}\text { Framework and Architecture for } \\
\text { Programming Education Environment as } \\
\text { a Cloud Computing Service [8]. }\end{array}$ & $\begin{array}{l}\text { Services such as logging of programming activities, program } \\
\text { plagiarism detection, programming workbook and automatic } \\
\text { marking lift as future work. }\end{array}$ \\
\hline $\begin{array}{l}\text { Teaching cloud computing: A software } \\
\text { engineering perspective [9]. }\end{array}$ & $\begin{array}{l}\text { - The charging system used by cloud provider may not be } \\
\text { acceptable by institution because it based on credit card. } \\
\text { - University staff may not have the skill for introduction of } \\
\text { high-quality cloud computing courses. }\end{array}$ \\
\hline $\begin{array}{l}\text { Research on Remote Collaborative } \\
\text { Engineering Practices for Master of } \\
\text { Software Engineering based on Cloud } \\
\text { Computing Environment [10]. }\end{array}$ & $\begin{array}{l}\text { - The courses in this project strictly belong to engineering } \\
\text { practice course. }\end{array}$ \\
\hline $\begin{array}{l}\text { Virtual Labs for Electronics Engineering } \\
\text { using Cloud Computing [11]. }\end{array}$ & $\begin{array}{l}\text { - It enables the communication between one student who do } \\
\text { experiment and the teacher who send the feedback. } \\
\text { - There is some future work to enhance this system for more } \\
\text { effective learning. }\end{array}$ \\
\hline $\begin{array}{l}\text { The Necessity Of Using Cloud } \\
\text { Computing In Educational System [12]. }\end{array}$ & $\begin{array}{l}\text { - Some of students and teaching staff may not experiences in } \\
\text { cloud computing. }\end{array}$ \\
\hline $\begin{array}{l}\text { New Instructional Models for Building } \\
\text { Effective Curricula on Cloud Computing } \\
\text { Technologies and Engineering [13]. }\end{array}$ & $\begin{array}{l}\text { - Any new course must be supported with a well-defined } \\
\text { Common Knowledge Base of the target professional } \\
\text { education domain and corresponding architecture framework } \\
\text { and that will be default to establish in new area such as cloud } \\
\text { computing. }\end{array}$ \\
\hline $\begin{array}{l}\text { Cloud Paradigms and Practices for } \\
\text { computational and data enabled science } \\
\text { and engineering [14]. }\end{array}$ & $\begin{array}{l}\text { - (CDS\&E) leads to a challenging socio technical research } \\
\text { agenda. }\end{array}$ \\
\hline $\begin{array}{l}\text { NIGEDU CLOUD: Model of a National } \\
\text { e-Education Cloud for Developing } \\
\text { Countries [15]. }\end{array}$ & $\begin{array}{l}\text { - The need for further researches to identify the best practices } \\
\text { that would address the variety of pedagogical, social- } \\
\text { cultural, technical, political, and economic issues } \\
\text { surrounding the adoption of such national cloud } \\
\text { infrastructures and services. }\end{array}$ \\
\hline $\begin{array}{l}\text { Observations of achievement and } \\
\text { motivation in using cloud computing } \\
\text { driven CAD: Comparison of college } \\
\text { students with high school and vocational } \\
\text { high school backgrounds [16]. }\end{array}$ & $\begin{array}{l}\text { - The students have to appreciate the usefulness of technology, } \\
\text { to become more motivated and participate in technological } \\
\text { education. } \\
\text { - The current study has failed to further examine the effect of } \\
\text { CAD courses. }\end{array}$ \\
\hline $\begin{array}{l}\text { The effect of cloud computing } \\
\text { technology in personalization and } \\
\text { education improvements and its } \\
\text { challenges [17]. }\end{array}$ & $\begin{array}{l}\text { - In order to use the advantages of modern educations and } \\
\text { other services, cost and speed of learning should be } \\
\text { considered }\end{array}$ \\
\hline $\begin{array}{l}\text { Cloud Computing Education Strategies } \\
\text { [18]. }\end{array}$ & $\begin{array}{l}\text { - The courses that address enough details will need } \\
\text { professional teaching staff in Cloud Computing. }\end{array}$ \\
\hline
\end{tabular}

better education outcome in developing. But, that leads to the need for further researches to identify the best practices that would address the variety of pedagogical, social-cultural, technical, political, and economic issues surrounding the adoption of such national cloud infrastructures and services [15].

Jou et al. [16] analyzed the academic performances induced by the exploitation of resources driven by cloud computing technologies. For education in engineering, virtualization of computer resources will enable students' access to licensed software from any from any laboratories on campus, facilitating ubiquitous access to expensive applications. The results show that college students with high school background seemed to possess higher learning incentive in computer-aided designing (CAD) applications. But, the current study has failed to 
investigate the effects of CAD course [16].

The speed of information technology growth has created a scheme that organizations should have required capabilities to encounter it keep with growth and development [17]. In cloud computing environment, there are various services including education services, offering software and resources to meet our needs. It is important in cloud computing to service composition and presenting virtual machine based on student's requirements and abilities. Various parameters should be considered such as cost and speed of learning in order to use the advantages of modern educations and other services [17].

Breivold et al. [18] present a number of strategies for teaching Cloud Computing. This is because the current CC courses do not address enough details and cloudrelated topics such as cloud-based architectures and develop and update applications. There is a lack of utilization of real-world systems in CC courses. Breivold et al. [18] propose strategies to include key knowledge areas while offering a $\mathrm{CC}$ courses but it requires professional teaching staff [18]. Table 1 shows the summary of related work.

\section{Problem Statement}

The students of master program face difficulties in Saudi Arabia either the desirable courses in their area are not offered or lab facilities are not adequate to do practical sessions. In addition, students of most universities in Saudi Arabia suffer from traditional ways of teaching due to lack of experts and professionals across the country. This paper attempts to address the need to utilize cloud computing in education in all major courses in order to raise the level of higher education in Saudi Arabia.

There are two research questions in hand.

- How to train the educators and students to be more experienced in cloud computing [12]?

- How to realize the usefulness of cloud computing to the educators and students so that they become more effective and beneficial for the society [16]?

\section{THE PROPOSED SOLUTION}

The present needs of higher education students in Saudi Arabia are to offer more attractive, creative and advanced courses using CC technology. Students can register the $\mathrm{CC}$ based courses from all universities of Kingdom. It is quite clear to the students of Saudi Arabia that the traditional approaches of teaching are unable to provide the necessary skills that are required in industry. The need of higher education can be fulfilled by incorporating the cloud computing courses in all disciplines. Cloud computing is reducing the differences between on campus and off campus activities. It can also provide solutions to many of the challenges encountered to the educational institutions to offer specialized courses at post graduate level. This paper proposed a novel solution to raise the level of higher education in Kingdom of Saudi Arabia. The proposed solution is composed of four goals.

A. Ascertain The Readiness And Willingness Of All Disciplines To Deal With Cloud By Taking Basic Cloud Computing Courses

All the top universities in Kingdom must offer courses on cloud computing. Therefore, students can have enough exposure and well equipped with the required knowledge of cloud computing to take benefits out of it. However, teachers and students should be willing and motivated to use services of cloud computing. The fundamental CC course covers introductory materials, principles and key characteristics from three perspectives. These perspectives are sensitization, practice and principles. According to the study in [19], students and teachers should understand the fundamental principles of a subject to be more comprehensive. Furthermore, students and faculty can grasp fundamental ideas and condense information about CC. Even students and faculty of unscientific fields should take CC courses to motivate the culture of up to date knowledge and research. Culture, Geography, Arts are some examples of nonscientific fields should be equipped with cloud computing courses.

\section{B. Implement Online Education Based On Cloud Computing Environments}

Universities should utilize the cloud infrastructure to share numerous education materials such as reference books, videos, online lecture and virtual class rooms. Online education will enable students to communicate with experts and professionals of top most universities of the world. It is economical and time saving for students and faculty by cutting down the transportation activity. Students at different locations can get benefit by attending lectures through virtual class rooms. Faculty can be hired from different geographical regions. The part time students who have some problems during normal working hours can be benefitted. CC should be implemented not only for the practical courses but also for non-practical courses like history, linguistics and literature. Students can communicate with professionals and experts of the specialized areas using CC technology. A survey is conducted by the IBM and it is reported that learners could learn in less time through the modern methods of learning as compared to traditional teaching methods [20]. In addition, teachers can update their knowledge and skills through modern educational technologies. Cloud computing has an important place in the higher education both as a universal computing tool and a powerful platform. Using cloud services, teachers and students can achieve mobility because of wired and wireless technologies. The online education is equally beneficial to full time and part time students.

\section{Apply Virtual Laboratories For All Disciplines}

Cloud computing usability in education is wideranging as it is acknowledged by many educational institutions around the world. It is proposed that 
universities will provide cloud-based laboratories to students while removing temporal and spatial boundaries. Students will carry out the experiments in a virtual environment. The cloud-based labs simulate the instruments that are typically used in the real labs to conclude the results and these results can be shared among the professionals and faculties to validate the results. There are few examples of existing CC laboratories like software engineering courses lab, electronics engineering lab and virtual computer network laboratory (CenLavi) [10][11][21].

It is proposed to use $\mathrm{CC}$ laboratories for nonscientific courses such as Geography, Linguistics and Arts. The students of Geography subject will use CC labs, without the need for field studies, to study online maps, simulate sediment biomarker laboratory, data analysis and share results with other educators. Similarly, the students of Linguistics courses will use cloud-based labs to communicate with the experts of their areas of expertise globally to improve their skills in a specific language. The students of Arts courses will use cloud-based lab to draw their artworks to learn, share and evaluate by the experts. Furthermore, students will learn processes and inspirations of the field experts across the word. Faculties and students can implement collaborative learning using CC-based labs. It will enable the learner to achieve higher cognitive abilities in a specific subject and get real time expert's feedback.

\section{Measure The Effectiveness Of Cloud-Computing For All Disciplines}

The reason that cloud computing is popular in the education sector because it offers extraordinary levels of efficiency, flexibility and value. The efficiency of existing resources will improve significantly by applying cloud computing in higher education. Cloud computing facilitates distance education by integrating and sharing resources to assist teachers and students. Fig. 1 shows how four goals achieve better education utilizing cloud computing.

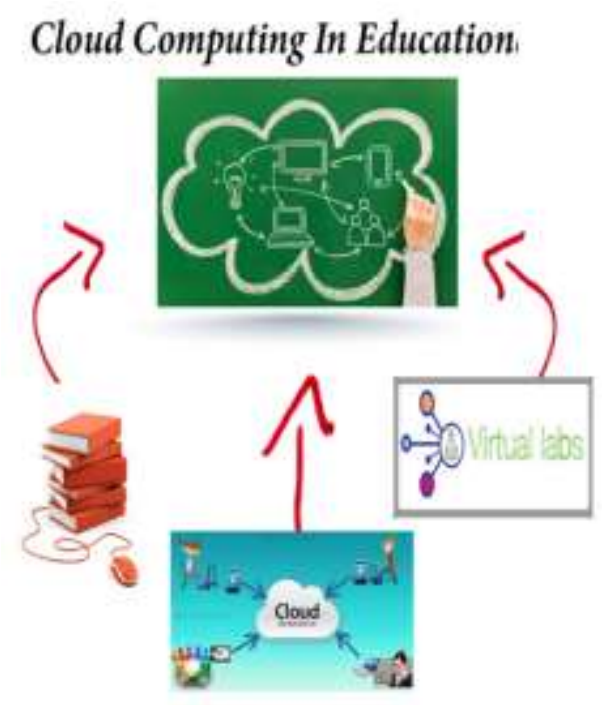

Fig. 1. The Proposed solution of Cloud Computing in Education

\section{VALIDATION}

A survey is conducted to evaluate the proposed solution. A questionnaire is designed that is consisting of fourteen close ended questions that are further divided into four goals. A sample size of thirty two professionals is collected against the four goals to statistically analyze and interpret. Goal 1 is to ascertain the readiness and willingness of all disciplines to deal with cloud by taking basic cloud computing courses. Goal 2 is to implement online education based on cloud computing environments Goal 3 is to apply virtual laboratories for all disciplines. Goal 4 is to measure the effectiveness of cloudcomputing for all disciplines. Likert scale one to five is used to evaluate the questions from very low to very high. The results are shown in the form of frequency tables and bar charts.

A. Goal 1-Cumulative Statistical Analysis of Goal 1. Ascertain The Readiness And Willingness of All Disciplines To Deal With Cloud By Taking Basic Cloud Computing Courses

Three questions are asked to evaluate the goal 1 . Cumulative results of three questions are shown in Table 2 and fig. 2. Table shows that that $10 \%$ of the responses are nominal, $6 \%$ and $1.3 \%$ of the professionals are in support of low and very low subsequently, $9.3 \%$ of the respondents are in favor of high and $5.3 \%$ of responses are very highly favoring to goal 1 .

Table 2. Cumulative analysis of Goal 1

\begin{tabular}{|c|c|c|c|c|c|}
\hline $\begin{array}{c}\text { Q. } \\
\text { No }\end{array}$ & $\begin{array}{c}\text { Very } \\
\text { low }\end{array}$ & Low & Nominal & High & $\begin{array}{c}\text { Very } \\
\text { high }\end{array}$ \\
\hline 1 & 1 & 6 & 12 & 9 & 4 \\
\hline 2 & 3 & 11 & 10 & 4 & 4 \\
\hline 3 & 0 & 1 & 8 & 15 & 8 \\
\hline Total & 4 & 18 & 30 & 28 & 16 \\
\hline Avg. & 1.3 & 6 & 10 & 9.3 & 5.3 \\
\hline
\end{tabular}

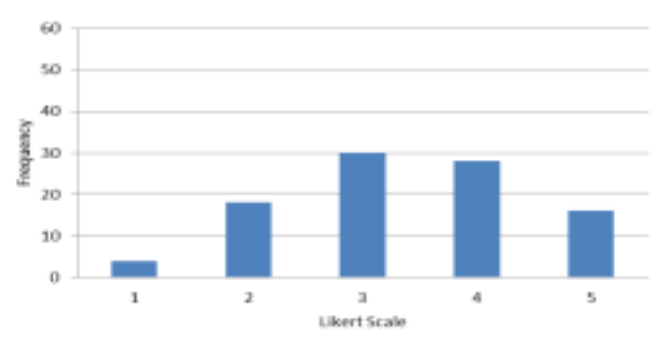

Fig. 2. Cumulative Analysis of Goal 1

B. Goal 2-Cumulative Statistical Analysis of Goal 2. Implement Online Education Based On Cloud Computing Environments

Goal 2 is evaluated by three questions. Table 3 shows cumulative results of goal 2 . Table 3 shows that $11 \%$ of responses are highly supporting the goal 2, 5.25\% of the responses are very high, $7.25 \%$ of the respondents are supporting to nominal, $6.75 \%$ of the participants are supporting low to goal 2 and $1.75 \%$ of the professionals are in support of very low. Fig. 3 depicts the results of Table 3 graphically. 
Table 3. Cumulative analysis of Goal 2

\begin{tabular}{|c|c|c|c|c|c|}
\hline Q. No. & $\begin{array}{c}\text { Very } \\
\text { low }\end{array}$ & Low & Nominal & High & $\begin{array}{c}\text { Very } \\
\text { high }\end{array}$ \\
\hline 1 & 5 & 13 & 5 & 6 & 3 \\
\hline 2 & 0 & 6 & 9 & 12 & 5 \\
\hline 3 & 0 & 4 & 7 & 13 & 8 \\
\hline 4 & 2 & 4 & 8 & 13 & 5 \\
\hline Total & 7 & 27 & 29 & 44 & 21 \\
\hline Avg. & 1.75 & 6.75 & 7.25 & 11 & 5.25 \\
\hline
\end{tabular}

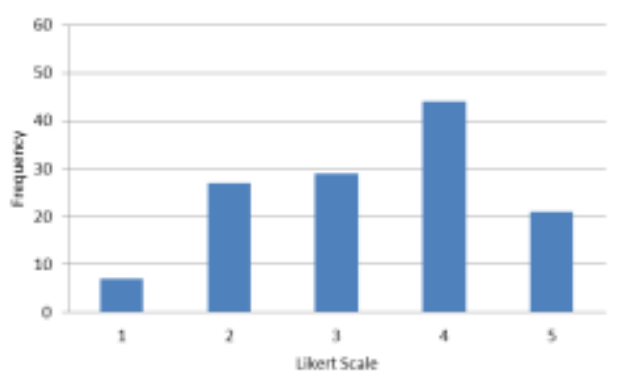

Fig. 3. Cumulative Analysis of Goal 2

\section{Cumulative Statistical Analysis Of Goal 3. Apply} Virtual Laboratories For All Disciplines

Four questions are evaluated in the questionnaire against goal 3 to conclude the results. Table 4 shows that $13.5 \%$ of responses are favoring high to goal $3,5.75 \%$ of the professionals are very high agreed to it, $8.25 \%$ of the respondents are in support of nominal, $4.25 \%$ of responses are in favor of low and $0.25 \%$ of the participants support to very low to goal 3. Fig. 4 displays the results of Table 4 graphically.

Table 4. Cumulative analysis of Goal 3

\begin{tabular}{|c|c|c|c|c|c|}
\hline Q. No & $\begin{array}{c}\text { Very } \\
\text { low }\end{array}$ & Low & Nominal & High & $\begin{array}{c}\text { Very } \\
\text { high }\end{array}$ \\
\hline 1 & 0 & 2 & 8 & 16 & 6 \\
\hline 2 & 0 & 2 & 5 & 17 & 8 \\
\hline 3 & 0 & 6 & 10 & 11 & 5 \\
\hline 4 & 1 & 7 & 10 & 10 & 4 \\
\hline Total & 1 & 17 & 33 & 54 & 23 \\
\hline Avg. & 0.25 & 4.25 & 8.25 & 13.5 & 5.75 \\
\hline
\end{tabular}

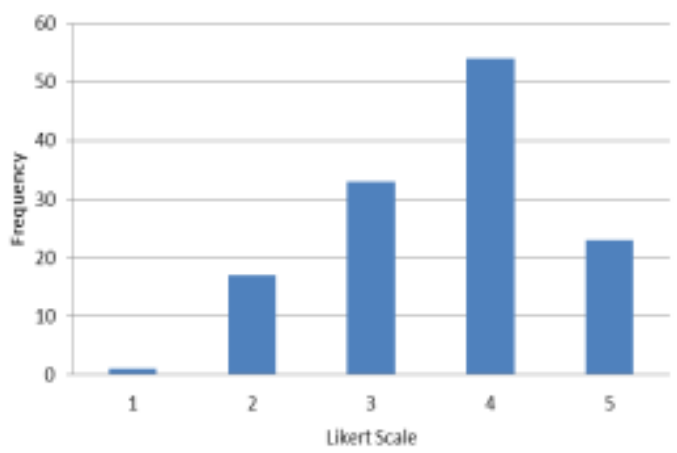

Fig. 4. Cumulative Analysis of Goal 3

D. Cumulative Statistical Analysis Of Goal 4. Measure The Effectiveness of Cloud-Computing For All Disciplines
Goal 4 is evaluated by three questions and the results of cumulative analysis are shown in Table 5 and fig. 5 . Table 5 shows that the $13.3 \%$ of responses are retained nominal, $12.67 \%$ of the respondents are highly agreed, $4.67 \%$ of the participants are supporting to very high and $1.3 \%$ of the professionals are in favor of low. Fig. 5 presents the results of Table 5 graphically.

Table 5. Cumulative analysis of Goal 4

\begin{tabular}{|c|c|c|c|c|c|}
\hline $\begin{array}{c}\text { Q. } \\
\text { No }\end{array}$ & $\begin{array}{c}\text { Very } \\
\text { low }\end{array}$ & Low & Nominal & High & $\begin{array}{c}\text { Very } \\
\text { high }\end{array}$ \\
\hline 1 & 0 & 2 & 15 & 12 & 3 \\
\hline 2 & 0 & 2 & 12 & 12 & 6 \\
\hline 3 & 0 & 0 & 13 & 14 & 5 \\
\hline Total & 0 & 4 & 40 & 38 & 14 \\
\hline Avg. & 0 & 1.3 & 13.3 & 12.67 & 4.67 \\
\hline
\end{tabular}

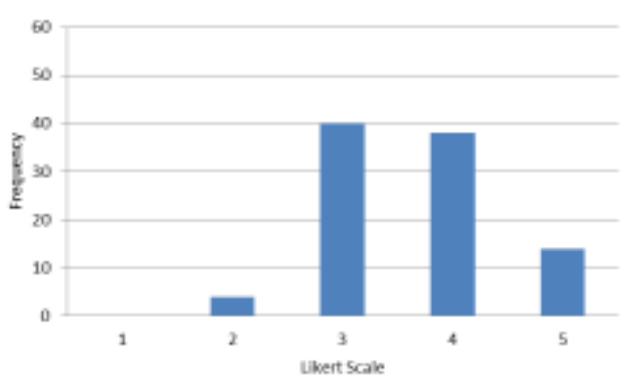

Fig. 5. Cumulative Analysis of Goal 4

\section{CONCLUSION}

The idea to use cloud computing in higher education is not new. This research attempts to use cloud computing technology in higher education in Kingdom of Saudi Arabia. The objective is to improve the level of higher education inside the Kingdom to solve the problems those are associated to learning process. In addition, this research will provide a roadmap to apply cloud computing in higher education for educators and students. First, prepare the students to involve in cloud computing technology by introducing the basic cloud computing courses. Second, apply online classes and virtual laboratories based on cloud environment. Finally, measure the effectiveness of cloud-computing technology for all disciplines. A survey is conducted to evaluate the proposed solution. The responses to the survey show that the majority of IT professionals and faculty are agreed to induct cloud computing with the traditional methods of teaching and learning to raise the level of higher education in Saudi Arabia.

\section{ACKNOWLEDGEMENTS}

After depending on Allah Almighty, this research was completed after several months of continuous work. First of all, thank to Allah and then to my family and friends who supported me throughout this research. Very special and sincere thanks to my supervisor Dr. M. Rizwan 
Jameel Qureshi to accomplish this research. His guidance and assistance are valuable and generous. Least but not last, thanks and appreciation to all those people who helped me to complete this research.

\section{REFERENCES}

[1] Foster, Y. Zhao, I. Raicu, and S. Lu, "Cloud computing and grid computing 360-degree compared," in Grid Computing Environments Workshop, 2008. GCE'08, 2008, pp. $1-10$.

[2] L. Wang, J. Tao, M. Kunze, A. C. Castellanos, D. Kramer, and W. Karl, "Scientific Cloud Computing: Early Definition and Experience," in HPCC, 2008, pp. 825-830.

[3] W. D. Yu and H. Yuan, "An approach to explore mobile software engineering advances in cloud computing environment," in Computer Software and Applications Conference Workshops (COMPSACW), 2011 IEEE 35th Annual, 2011, pp. 292-297.

[4] C. Haas, S. Caton, and C. Weinhardt, "Engineering incentives in social clouds," in Cluster, Cloud and Grid Computing (CCGrid), 2011 11th IEEE/ACM International Symposium on, 2011, pp. 572-575.

[5] K. Chard, K. Bubendorfer, S. Caton, and O. F. Rana, "Social cloud computing: A vision for socially motivated resource sharing," Services Computing, IEEE Transactions on, vol. 5, pp. 551-563, 2012.

[6] S. Sazawa, M. Hashima, Y. Sato, K. Horio, and K. Matsui, "RVEC: Efficient Remote Desktop for the ENGINEERING CLOUD," in Advanced Information Networking and Applications Workshops (WAINA), 2012 26th International Conference on, 2012, pp. 1081-1088.

[7] M. García-Valls, T. Cucinotta, and C. Lu, "Challenges in real-time virtualization and predictable cloud computing," Journal of Systems Architecture, vol. 60, pp. 726-740, 2014.

[8] A. M. Elamir, N. Jailani, and M. A. Bakar, "Framework and Architecture for Programming Education Environment as a Cloud Computing Service," Procedia Technology, vol. 11, pp. 1299-1308, 2013.

[9] I. Sommerville, "Teaching cloud computing: a software engineering perspective," Journal of Systems and Software, vol. 86, pp. 2330-2332, 2013.

[10] Q. Ding, X. Li, Y. Liu, and Z. Shi, "Research on Remote Collaborative Engineering Practices for Master of Software Engineering Based on Cloud Computing Environment," in Software Engineering Education and Training (CSEE\&T), 2012 IEEE 25th Conference on, 2012, pp. 110-114.

[11] D. Bagchi, K. Kaushik, and B. Kapoor, "Virtual labs for electronics engineering using cloud computing," in Interdisciplinary Engineering Design Education Conference (IEDEC), 2013 3rd, 2013, pp. 39-40.

[12] A. Bouyer and B. Arasteh, "The Necessity of Using Cloud Computing in Educational System," Procedia-Social and Behavioral Sciences, vol. 143, pp. 581-585, 2014.

[13] Y. Demchenko, D. Bernstein, A. Belloum, A. Oprescu, T. W. Wlodarczyk, and C. d. Laat, "New Instructional Models for Building Effective Curricula on Cloud Computing Technologies and Engineering," in Cloud Computing Technology and Science (CloudCom), 2013 IEEE 5th International Conference on, 2013, pp. 112-119.

[14] M. Parashar, M. AbdelBaky, I. Rodero, and A. Devarakonda, "Cloud paradigms and practices for computational and data-enabled science and engineering," Computing in Science \& Engineering, vol. 15, pp. 10-18, 2013.
[15] A. Ezenwoke, N. Omoregbe, C. K. Ayo, and M. Sanjay, "NIGEDU CLOUD: Model of a National e-Education Cloud for Developing Countries," IERI Procedia, vol. 4, pp. 74-80, 2013.

[16] M. Jou and J. Wang, "Observations of achievement and motivation in using cloud computing driven CAD: Comparison of college students with high school and vocational high school backgrounds," Computers in Human Behavior, vol. 29, pp. 364-369, 2013.

[17] M. Jalali, A. Bouyer, B. Arasteh, and M. Moloudi, "The Effect of Cloud Computing Technology in Personalization and Education Improvements and its Challenges," Procedia-Social and Behavioral Sciences, vol. 83, pp. 655-658, 2013.

[18] H. P. Breivold and I. Crnkovic, "Cloud Computing education strategies," in Software Engineering Education and Training (CSEE\&T), 2014 IEEE 27th Conference on, 2014, pp. 29-38.

[19] A. Schwill, "Computer science education based on fundamental ideas," Samways, Brain (Hrsg.): Information Technology-Supporting change through teacher education London: Chapman \& Hall, pp. 285-291, 1997.

[20] I. G. Education, "Virtualization in education," white Paper, 2007.

[21] N. H. Tran, H. D. Tran, P. T. Chiem, D. T. Luu, T. D. Cao, and P. Kaskenpalo, "CenLavi: Virtual Computer Network Laboratory," in Ubiquitous and Future Networks (ICUFN), 2013 Fifth International Conference on, 2013, pp. 523-528.

\section{Authors' Profiles}

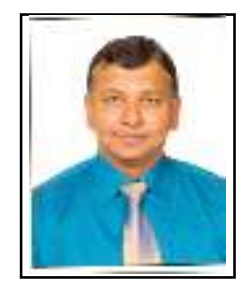

Dr. M. Rizwan Jameel Qureshi received his Ph.D. degree from National College of Business Administration \& Economics, Pakistan in 2009. He is currently working as an Associate Professor in the Department of IT, King Abdulaziz University, Jeddah, Saudi Arabia. This author is the best researcher awardees from the Department of Information Technology, King Abdulaziz University in 2013 and the Department of Computer Science, COMSATS Institute of Information Technology, Lahore, Pakistan in 2008.

Bayan Hashr Alamri is currently doing master in IT from Faculty of Computing \& Information Technology, King Abdulaziz University, Saudi Arabia. She is a graduate of Taibah University, Saudi Arabia.

How to cite this paper: Bayan Hashr Alamri, M. Rizwan Jameel Qureshi,"Usability of Cloud Computing to Improve Higher Education", International Journal of Information Technology and Computer Science(IJITCS), vol.7, no.9, pp.5965, 2015. DOI: $10.5815 /$ ijitcs.2015.09.09 